DOI: $10.17805 /$ zpu.2016.4.15

\title{
Методика индексного исследования гражданской активности для регионов Российской Федерации*
}

\author{
А. А. ФРОЛОВ
}

(ЯРОСЛАВСКИЙ ГОСУДАРСТВЕННЫЙ УНИВЕРСИТЕТ ИМ. П. Г. ДЕМИДОВА)

В современной России получают развитие разнообразные формы и институты гражданского общества. При этом сам феномен гражданской активности в современной России остается слабо исследованной относительно иных категорий политической науки. Он требует детального и обстоятельного подхода. Попытка индексного анализа гражданской активности - это относительно новое и перспективное направление российской политической науки. Развитие индексных исследований связано с глобальными общественными изменениями, такими как демократизация и глобализация. В то же время развитие получают и разнообразные региональные исследования. В статье приводятся примеры суще-

* Исследование выполнено при финансовой поддержке РФФИ в рамках научного проекта № 16-36-00314 мол_а «Индексное исследование гражданской активности в субъектах Российской Федерации (на примере Ярославской области)».

The study was performed with financial support from the Russian Foundation for the Basic Research, Project No. 16-36-00314 mol_a «Index analysis of civic activity in regions of Russian Federation (on the example of the Yaroslavl region)». 
ствующих в стране индексных исследований, связанных с вопросами изучения гражданской активности и гражданского общества.

В работе представлена теоретическая основа индексного исследования гражданской активности, в которую включены теории относительной депривации, коллективного действия и идентичности. Индекс гражданской активности направлен на определение уровня гражданской активности в конкретно взятом регионе Российской Федерации, учитывая при этом основные условия, факторы и особенности проявления гражданской активности.

Методика индексного исследования гражданской активности включает в себя проведение двух социологических исследований, выявляющих понимание и субъективный уровень развитости гражданского общества и гражданской активности отдельного региона страны. Методика расчета индекса представляет собой расчет среднего арифметического количества баллов, набранных группами респондентов в рамках проведения экспертного опроса и массового социологического опроса. Также в методике расчета индекса используются выравнивающие и весовые коэффициенты.

Конструирование и применение индекса гражданской активности в процессе своего применения отразит действительный уровень гражданской активности в регионах страны.

Ключевые слова: гражданская активность; гражданское общество; индекс гражданской активности; индексный анализ

\section{ВВЕАЕНИЕ}

D оссийская политическая наука, имея относительно небольшую историю существования, стремительно развивается: появляются новые объекты, предметы и методы исследования общественно-политических процессов. Обогащение происходит не только путем генерации или значительной модернизации теоретических основ изучения, но и путем анализа результатов проведения прикладных, как правило, узких по своей тематике исследований. В начале процесса построения и становления политической науки научное сообщество стремилось теоретизировать имеющийся политический опыт, разрабатывая фундаментальные и методологические проблемы. С течением времени и существенным укреплением науки проблематика исследований и научных изысканий сместилась от фундаментальной теории к прикладным исследованиям и моделированию политических процессов. На сегодняшний день, учитывая скоротечность изменения социальных и политических факторов, влияющих на российские общественно-политические процессы, категории гражданского общества и гражданской активности являются актуальной темой для исследований.

Гражданская активность является довольно динамичным и изменчивым явлением, которое зависит от множества факторов как внешней, так и внутренней среды. Но именно это и делает ее актуальным явлением, требующим не только изучения самого понятия, но и исследования форм проявления и систематизации результатов. Гражданская активность в современной России остается слабо исследованной относительно иных категорий политической науки. Актуальность исследования гражданской активности объясняется демократизацией российского общества, возрастанием значимости и усложнения горизонтальных общественных связей. Также на все эти процессы влияет и высокий темп развития электронных средств коммуникации и компьютерных технологий в целом. Расширение форм и институтов гражданского общества развивает и стимулирует появление новых форм гражданской активности. В различных сферах общественных отношений наблюдается рост мобилизации отдельных граждан и общественных групп в решение актуальных социальных проблем. Влияние всех этих факторов трудно переоценить: они изменяют способы коммуникации граждан и мотивации людей к действию, привносят в общество новые 
социальные координаты. Вслед за плюральным и демократизирующимся обществом научные методы исследования также претерпевают свое изменение для более полного и точного отражения потребностей общества. В частности, данные проблемы ученые пытаются изучить при помощи формирования индексов, применяя для этого различные показатели.

\section{ИСПОАБЗОВАНИЕ ИНАЕКСОВ \\ В ПОАИТИЧЕСКОЙ НАУКЕ}

Использование индексов и применение индексного анализа в политической науке началось еще более шестидесяти лет назад, когда были разработаны индексы демократичности политического режима и индекс протеста, но в последние двадцать лет индексы используются наиболее активно (индекс политической конкуренции, индекс восприятия коррупции, индекс свободы прессы, индексы политического риска и человеческого развития). Сами индексы представляют собой формализованное с помощью применения математического аппарата представление социально-политической информации, как правило, ранжированное по выбранным исследователем показателям. Актуализацию индексного исследования можно соотнести с глобальными общественными изменениями, демократизацией, глобализацией и т. А.

Существует ряд наиболее авторитетных индексов, к которым апелдируют российские исследователи. К числу таких индексов можно отнести: индекс человеческого развития (ИЧР); индекс политии (автор Тед Роберт Гурр); индекс демократизации (автор Тату Ванханен); индекс глобализации («Foreign Affairs» \& A. T. Kearney); индекс трансформации Бертельсманна.

Среди отечественных примеров построения индексов, связанных с изучением процессов и категорий гражданского общества, можно выделить несколько. Одним из наиболее известных индексов, является авторский ЯН-индекс (В. Н. Якимец), который представляет собой инструмент для количественной оценки и мониторинга состояния публичной политики в регионах России (Якимец, 2011: 60). Аанный индекс строится на основе показателей, характеризующих состояние публичной сферы и степени открытости общества. ЯН-индекс - составной, строится из двух частных индексов, а именно ЯН-индекса развитости публичной сферы и ЯН-индекса демократизации общества.

AЯ-рейтинг регионов по уровню продвижения механизмов межсекторного социального партнерства (Якимец, 2008: 283) используется для сравнения территориальных образований РФ по уровню продвижения межсекторного социального партнерства. В индексе предложена рейтинговая методика оценки на основе факта наличия механизмов межсекторного социального партнерства в разных регионах страны.

Индекс гражданского общества от CIVIC (Всемирного альянса за гражданское участие) представлен в докладе «Гражданское общество в модернизирующейся России» и определяется как прикладной исследовательский проект по оценке состояния гражданского общества (Якобсон, Мерсиянова, 2011: Электронный ресурс). Индекс основан на принципах участия граждан в общественной жизни, который учитывает ряд измерений, таких как общественное участие, организованность гражданского общества, практикуемые ценности и другие показатели.

Индексные исследования гражданского общества являются новыми направлениями в российской политической науке. Каждый из представленных индексов является 
полноценным исследованием разных процессов и категорий гражданского общества. При разработке индекса гражданской активности особое внимание было уделено изучению ЯН-индекса (В. Н. Якимец), в частности, системе оценки показателей.

\section{ТЕОРЕТИЧЕСКАЯ ОСНОВА ИНАЕКСНОГО ИСАЕАОВАНИЯ ГРАЖААНСКОЙ АКТИВНОСТИ}

На данный момент в России все более актуальным становится изучение регионального аспекта проявления гражданской активности в соответствии с особенностями территории индексирования. Разрабатываемый индекс гражданской активности направлен на определение уровня гражданской активности в конкретно взятом регионе Российской Федерации, учитывая при этом основные условия, факторы и особенности проявления гражданской активности. В теоретическую основу индексного исследования гражданской активности включены основы теорий относительной депривации, коллективного действия и идентичности.

Одной из наиболее значимых теоретических основ изучения гражданской активности является теория относительной депривации. Эта теория широко распространена как в политической, так и в социологической науке. Относительную депривацию можно понимать как состояние значительной рассогласованности представления или ожидания человека о каком-либо предмете или явлении и фактического восприятия этого явления или предмета. Социально-политические и социально-экономические факторы значительно влияют на воспринимаемую населением картину социальной реальности, которая может проявляться на уровне удовлетворенности собственной жизнью или на соотношении ожиданий и достижений человека.

Понятия депривации и неудовлетворенности объединяют в себе множество психологических состояний человека, проявляющихся открыто или латентно. Им соответствуют такие понятия, как отчуждение, фрустрация, острая необходимость, управляемые и целенаправленные конфликты и социальное напряжение (Гарр, 2005: 51). В Большом толковом социологическом словаре А. Ажери и Аж. Ажери понятие относительной депривации определяется как вырабатываемые суждения и испытываемые чувства, когда индивид считает собственное положение в социуме неблагоприятным относительно других членов общества, с которыми он контактирует (Ажери А, Ажери Аж 1999: 534). А. Бляхер дает свою социально-философскую трактовку этого понятия, понимая под относительной депривацией индикатор степени социальной напряженности, а не проявление протеста посредством конкретных действий (Бляхер, 2005: 143). В свою очередь, Т. Гарр под относительной депривацией понимал значительное расхождение между ценностными долженствованиями и ценностными возможностями, воспринимаемыми индивидами (Гарр, 2005: 51).

Аругими словами, относительная депривация в большей степени отражает важность не объективных показателей социальной напряженности и протестного потенциала, а субъективных, динамичных показателей, показывающих различия имущественного или статусного отношения людей. Кумулятивный әффект относительной депривации может быть крайне деструктивным, так как абстрактное чувство неудовлетворенности может обрести политическую плоскость в довольно короткие сроки, повышая вероятность появления конфликта и применения в нем насильственных действий по отношению к противоборствующей или нейтральной стороне. Теория раскрывает динамичные показатели, демонстрирующие различия в понимании общественных процессов людьми, вопросы рассогласованности представлений или 
ожиданий людей о социальных явлениях, социальную напряженность и другие показатели.

В современной науке сложилось несколько подходов к понятию идентичности. Согласно М. Кастельсу, идентичность представляет собой процесс конструирования смысла на основе определенного культурного свойства или соответствующей совокупности культурных свойств, которые обладают приоритетом по отношению к другим источникам смысла (Castells, 1997: 6). У. Конноли считает, что «идентичность формируется по отношению к серии различий, которые социально осознаются. Эти различия основательны для ее существования. Если они не сосуществуют как различия, идентичность не существует в своей отличительности и устойчивости» (Connolly, 1991: 64). О. Ю. Малинова пишет о том, что «в современном обществе идентичности становятся все более множественными, фрагментарными, зависимыми от контекста, они имеют радикально исторический характер и постоянно находятся в состоянии изменения и трансформации» (Малинова, 2005: 8).

Современная политическая и социологическая научная литература оперирует двумя основными подходами к определению идентичности. Первый подход понимает идентичность относительно общей структуры психологических систем человека. Представители второго подхода понимают под идентичностью совокупность символических средств выражения идей, опосредующих отношение человека к социальным категориям, то есть он (подход) концентрируется на социологических аспектах. При попытке совмещения двух подходов появился третий, объединяющий в себе различные категории, подход, называемый теорией социальной идентичности (Tajfel, 2010). Аля исследования мы рассматриваем социальную идентичность, которая в своем общем виде представляет собой разветвленную когнитивную систему, включающую в себя как личностную, которая складывается из самоопределения нравственных, физических или интеллектуальных компонентов, так и социальную идентичность, определяющую принадлежность индивида к той или иной социальной группе. Также интересным становится гражданская идентичность, которую можно понимать как совокупность маркеров, обладающих высокой степенью идентичности, показывающих характер отношения к различным политическим институтам. Гражданскую идентичность можно определить как коммуникацию индивида с политическими институтами. Ей присуща субъектно-объектная модель взаимоотношений, в которой политические институты выступают в качестве символов идентичности, нивелируя значимость отдельных личностей. Гражданская идентичность включает в себя и элементы истории, культуры, языка, политической культуры и особенностей взаимодействия индивидов в обществе. Гражданская идентичность также рассматривает механизмы вовлечения и удержания субъектов на определенной территории. Здесь важную роль играет консолидация общества с политическими и властными институтами, которая строится на взаимодействии с символическими персонами, такими как глава региона, депутаты, символы региона и др. Взаимосвязь осуществляется через формальные и неформальные каналы коммуникации, такие как СМИ, социальные сети и разнообразные интернет-приложения. Теория раскрывает вопросы принадлежности индивида к той или иной социальной группе, его коммуникацию и характер отношения с различными политическим институтам.

Аругим важным теоретическим основанием исследования гражданской активности являются модели коллективного действия. Первые исследования коллективных действий выявили следующую закономерность: чем ниже субъективное восприятие 
своей группы в социальной иерархии, тем больше вероятность проявления коллективных действий, как правило, имеющих протестный характер (Postmes, Branscombe, Spears, Young, 1999: 320-338). Потенциал к проявлению протестных действий формируется на основе ощущения группой социальной несправедливости, которая появляется из осознания неравенства доступа к различным ресурсам (Simon, Klandermans, 2001: 319-331). Авижущей силой в данном случае можно считать уверенность людей в итоговых результатах совместных коллективных действий.

Одним из наиболее авторитетных современных теоретиков является М. Ван Зомерен, который предложил двухфакторную модель коллективных действий. Основными факторами теории являлись групповые эмоции и субъективная вероятность успешности коллективных действий группы (Van Zomeren, Spears, Fischer, Leach, 2004: 649-664). В условиях осознания социальной несправедливости группой ее вероятное поведение может приобрести несколько векторов своего развития: поиск эмоциональной поддержки у членов группы относительно сложившейся ситуации и коллективная артикуляция оценочного суждения. В таком векторе деструктивные чувства, испытываемые членами группы, возрастают и принимают кумулятивный әффект. Второй вектор развития - оценка действий других членов группы и поиск удовлетворения потребности в инструментальной поддержке. При обнаружении индивидом схожести действий других членов группы вероятность проявления коллективных протестных действий значительно увеличивается. Стоит отметить взаимодополняющий характер векторов развития событий. Таким образом, алгоритм проявления коллективного действия выглядит как принятие решения индивидом о значимости для него несправедливого положения группы; вторичная оценка значимости, прогнозирование последствий невыгодного положения группы и генерация эффективных механизмов для совладения со сложившейся ситуацией; поиск и оценка стратегий поведения группы. Теория раскрывает групповые эмоции и субъективную вероятность успешности коллективных действий разных групп, а также степень участия жителей в общественной жизни региона.

Вышеперечисленные теории относительной депривации, идентичности и коллективного действия хорошо показывают факторы, условия и причины различных действий людей. Стоит отметить, что, хотя различные теории довольно полно описывают модели поведения людей, их необходимо понимать как косвенные факторы, которые определяют не столько само поведение человека, сколько основные векторы действий. В проведении исследования гражданской активности необходимо генерировать критерии анализа информации. В исследование включаются субъективные показатели: степень доверия населения к тем или иным формам проявления гражданской активности, основные сложности, с которыми сталкиваются граждане при проявлении гражданской активности, стабильность гражданской позиции населения, а также ассоциацию граждан с определенной социальной группой, степень социальной несправедливости и основную мотивацию к действиям.

\section{МЕТОАИКА ИНАЕКСНОГО ИССАЕАОВАНИЯ ГРАЖААНСКОЙ АКТИВНОСТИ}

Разрабатываемый индекс гражданской активности направлен на сбор, формализацию и анализ полученной в ходе проведения социологического опроса информации в отдельно взятом регионе Российской Федерации. Социологическое исследование включает в себя опрос четырех групп респондентов в рамках экспертного опроса 
(служащие органов государственной и муниципальной власти; представители бизнеса, осуществляющие деятельность на территории региона; руководители некоммерческих организаций, зарегистрированных и осуществляющих деятельности на территории региона; представители региональных средств массовой информации) и опрос населения, сбор эмпирической информации, который предполагается провести посредством телефонного интервью по стандартизированной анкете.

Экспертный опрос имеет цель получить информацию о состоянии гражданского общества и гражданской активности; выявить особенности и уровень взаимодействия различных сфер (секторов) гражданского общества; выявить степени эффективности общественных организаций и уровень доверия к различным секторам гражданского общества. Обоснование выборки экспертов является внестатистическим и не предполагает расчет статистического оценивания ошибки выборки. Суммарное количество экспертов, взятое в равных пропорциях, отражает основных субъектов и партнеров гражданской активности. Общее количество экспертов в данном социологическом исследовании составляет 60 человек: численность каждой сферы (представителей государственной и муниципальной власти; руководителей НКО; представителей регионального бизнеса и СМИ) составляет 15 человек.

Опрос местного населения имеет целью выявление: субъективного уровня развитости гражданского общества и гражданской активности; уровня вовлеченности индивида в общественную жизнь; основных сложностей, препятствующих проявлению гражданской активности; эффективности основных форм вовлечения человека в общественную жизнь; значимость основных форм проявления гражданской активности и др. Проведение телефонного интервью обеспечит опрос населения выбранного для исследования региона. Также телефонное интервью минимизирует риск смещения выборки к той или иной социальной группе населения. Рекомендуемые показатели уровня достоверности социологических данных должны составлять 95\%; статистическая погрешность должна быть в диапазоне $\pm 3,1 \%$.

Каждой группе опрашиваемых респондентов будет выдан уникальный опросный лист, способствующий идентификации суждений и роли каждого субъекта гражданской активности. Вопросные листы для всех групп респондентов содержат в себе ряд закрытых вопросов, ответы на которые находятся в таблицах от 1 до 10, где значению 1 соответствует наименьший балл за ответ, а 10 - наиболее высокий балл.

Математический аппарат индекса направлен на выявление среднего арифметического значения ответов респондентов с дальнейшим сведением их к общему индексу с помощью выравнивающих коэффициентов, которые используются для компенсации разницы в количестве вопросов у разных групп респондентов. Выравнивающий коэффициент также применяется для повышения репрезентативности полученной информации, так как в опросных листах разных групп респондентов содержится разное количество вопросов, а соответственно, и возможного количества баллов. Также в индексе используется весовой коэффициент, который необходим для ранжирования результатов анкетирования экспертных групп по важности ответов той или иной группы.

Методика расчета индекса представляет собой расчет среднего арифметического количества баллов, набранных группами респондентов в рамках проведения экспертного опроса и массового социологического опроса. Аля каждой из групп респондентов предполагается расчет среднего арифметического количества набранных ими баллов. 
В формализованном виде среднее арифметическое всех вопросов и групп респондентов выглядит как

$$
\sum_{L=1}^{\mathrm{W}} \sum_{\substack{p=1 \\ w * \nu * n * m}}^{n} \sum_{i=1}^{n} \sum_{j=1}^{m} \text { OjibL }
$$

где переменными будут: $n-$ количество вопросов; $m$ - количество респондентов; $v-$ количество групп респондентов; $w$ - количество районов в регионе; $v$ - номер вопроса; $j$ - номер респондента; $L$ - номер района; $p$ - номер группы. Аля более подробной работы с данными в индексе существуют формулы для установления количества баллов всех вопросов и групп респондентов в отдельно взятом районе области, по отдельно взятому вопросу в отдельно взятом районе всех групп респондентов, отдельной группы респондентов в отдельном районе; в определенной группе выбранного района и др.

По результатам проведения индексного анализа, информация будет показана с помощью гистограммы гражданской активности, раскрывающей разные региональные аспекты взаимодействия субъектов гражданского общества.

\section{ЗАКАЮЧЕНИЕ}

Подводя итоги, можно сказать о том, что гражданская активность является относительно новой, актуальной проблемой для исследования, требующей детального и обстоятельного подхода к ней на различных уровнях Российской Федерации. Актуальным становиться применение разнообразных индексных исследований, которые раскрывают разные показатели развития и взаимодействия общества и государства. Опыт индексного анализа гражданской активности - это относительно новое направление российской политической науки. Существует только несколько отечественных примеров построения индексов, связанных с изучением процессов и категорий гражданского общества.

Создание индексной методики исследования гражданской активности для регионов Российской Федерации - это актуальное направление изучения вопросов гражданского общества и гражданской активности. Разработанная методика выявляет понимание и субъективный уровень развитости гражданского общества и гражданской активности отдельного субъекта страны.

Применение данного индекса в разных регионах Российской Федерации позволит раскрыть вопросы взаимодействия институтов власти с гражданским обществом, провести комплексный анализ основных форм проявления гражданской активности. Одним из ключевых аспектов дальнейших исследований станет выявление степени вовлеченности населения в общественную жизнь, а также выявление наиболее эффективных механизмов и субъектов гражданского общества, способствующих проявлению гражданской активности в регионах страны.

\section{СПИСОК АИТЕРАТУРЫ}

Бляхер, $\Lambda$. Е. (2005) Нестабильные социальные состояния. М. : Российская политическая энциклопедия. 208 с.

Гарр, Т. (2005) Почему люди бунтуют : пер. с англ. СПб. : Питер. 464 с.

Ажери, А., Ажери Аж. (1999) Большой толковый социологический словарь: в 2 т. : пер. с англ. М. : Вече ; АСТ. Т. 1 (А-O). 544 с. 
Малинова, О. Ю. (2005) Идентичность как категория практики и научного анализа: о различии подходов // Права человека и проблемы идентичности в России и в современном мире / под ред. О. Ю. Малиновой, А. Ю. Сунгурова. СПб. : Норма, 272 с. С. 6-13.

Якимец, В. Н. (2008) О социологическом мониторинге состояния гражданского общества в России // Труды Института системного анализа Российской академии наук. Т. 32. C. $275-287$.

Якимец, В. Н. (2011) Публичная политика в регионах России: индекс оценки, межрегиональные сравнения и направления развития // Вестник Московского ун-та. Сер. 12. Политические науки. № 1. С. 59-67.

Якобсон, А. И., Мерсиянова, И. В. (2011) Гражданское общество в модернизирующейся России [Электронный ресурс] // Аналитический доклад Центра исследований гражданского общества и некоммерческого сектора Национального исследовательского университета «Высшая школа экономики» по итогам реализации проекта «Индекс гражданского общества CIVICUS». URL: http://www.portal-nko.ru/files/OrgNewsItem/774/Files/2/civicus_russia_rus.pdf (дата обращения 15.09.2016).

Castells, M. (1997) The power of identity. Cambridge, Mass. : Blackwell. 4613.

Connolly, W. E. (1991) Identity. Difference: Democratic negotiations of political paradox. Ithaca : Cornell Univ. press. 278 p.

Postmes, T., Branscombe, N. R., Spears, R., Young, H. (1999) Comparative Processes in Personal and Group Judgments: Resolving the Discrepancy // Journal of Personality and Social Psychology. Vol. 76. P. 320-338.

Simon, B., Klandermans, B. (2001) Politicized Collective Identity. A Social Psychological Analysis // American Psychologist. Vol. 56. № 4. P. 319-331. p. 523.

Tajfel, H. (2010) Social identity and intergroup relations. Cambridge : Cambridge Univ. Press.

Van Zomeren, M., Spears, R., Fischer, A. H., Leach, CW. (2004) Put Your Money Where Your Mouth Is! Explaining Collective Action. Tendencies Through Group-Based Anger and Group Efficacy // Journal of Personality and Social Psychology. Vol. 87. № 5. P. 649-664.

Аата поступления: 28.10.2016 г.

INDEX ANALYSIS OF CIVIC ACTIVITY

IN THE REGIONS OF RUSSIAN FEDERATION

A. A. FROLOV

(Demidov Yaroslavl State University)

Contemporary Russia has a variety of forms and institutions of civil society, while the phenomenon of civic activism in remains understudied in comparison with other categories of political science. Civic activism requires a detailed and thorough focus of a researcher. Index analysis of civic engagement is a relatively new and promising direction in Russian political science. The rise of index studies is related to global social changes, such as democratization and globalization. At the same time, regional studies are also developing. The article provides examples of current index studies of civic engagement and civil society.

The paper presents the theoretical background to the index study of civic engagement, which includes the theories of relative deprivation, collective action and identity. The index of civic engagement is aimed at assessing civic activity within a particular region of the Russian Federation, with respect to its basic conditions, factors and specific manifestations.

The methodology involves performing two separate sociological studies of the levels of understanding and subjective development of civil society and civic engagement in a given region. The index is calculated as the simple average of the points which respondent groups have scored in expert survey and mass polling, adjusted for leveling and weight quotients. 
Constructing and using the Index of civic engagement helps assess the true level of civic activity in various regions of the Russian Federation.

Keywords: civic engagement; civil society; index of civic engagement; index analysis

\section{REFERENCES}

Bliakher, L. E. (2005) Nestabil'nye sotsial'nye sostoianiia. Moscow, Rossiiskaia politicheskaia entsiklopediia. 208 p. (In Russ.)

Gurr, T. (2005) Pochemu liudi buntuiut. by Engl. St. Petersburg, Piter. 464 p. (In Russ.)

Jary, D. and Jary, J. (1999) Bol'shoi tolkovyi sotsiologicheskii slovar': in 2 vol. Moscow, Veche, AST. Vol. 1 (A-O). 544 p. (In Russ.)

Malinova, O. Yu. (2005) Identichnost' kak kategoriia praktiki i nauchnogo analiza: o razlichii podkhodov. In: Prava cheloveka i problemy identichnosti $v$ Rossii i v sovremennom, ed. O. Yu. Malinova and A. Yu. Sungurov. St. Petersburg, Norma. 272 p. Pp. 6-13. (In Russ.)

Yakimets, V. N. (2008) O sotsiologicheskom monitoringe sostoianiia grazhdanskogo obshchestva v Rossii. Trudy Instituta Sistemnogo analiza Rossiiskoi Akademii Nauk, vol. 32, pp. 275-287. (In Russ.)

Yakimets, V. N. (2011) Publichnaia politika v regionakh Rossii: indeks otsenki, mezhregional'nye sravneniia i napravleniia razvitiia. Vestnik Moskovskogo un-ta, issue 12. Politicheskie nauki, no. 1, pp. 59-67. (In Russ.)

Yakobson, L. I. and Mersiianova, I. V. (2011) Grazhdanskoe obshchestvo v moderniziruiushcheisia Rossii. Analiticheskii doklad Tsentra issledovanii grazbdanskogo obshchestva i nekommercheskogo sektora Natsional'nogo issledovatel'skogo universiteta "Vysshaia shkola ekonomiki» po itogam realizatsii proekta "Indeks grazhdanskogo obshchestva - CIVICUS》 [online] Available at: http://www.portal-nko.ru/files/OrgNewsItem/774/Files/2/civicus_russia_rus.pdf (access data: 15.09.2016). (In Russ.)

Castells, M. (1997) The power of identity. Cambridge, Mass, Blackwell. 461 p.

Connolly, W. E. (1991) Identity. Difference: Democratic negotiations of political paradox. Ithaca, Cornell Univ. press. 278 p.

Postmes, T., Branscombe, N. R., Spears, R. and Young, H. (1999) Comparative Processes in Personal and Group Judgments: Resolving the Discrepancy. Journal of Personality and Social Psychology, vol. 76, pp. 320-338.

Simon, V. and Klandermans, B. (2001) Politicized Collective Identity. A Social Psychological Analysis. American Psychologist, vol. 56, no. 4, pp. 319-331.

Tajfel, H. (2010) Social identity and intergroup relations. Cambridge, Cambridge Univ. Press. $523 \mathrm{p}$.

Van Zomeren, M., Spears, R., Fischer, A. H. and Leach, CW. (2004) Put Your Money Where Your Mouth Is! Explaining Collective Action. Tendencies Through Group-Based Anger and Group Efficacy. Journal of Personality and Social Psychology, vol. 87, no. 5, pp. 649-664.

Submission date: 28.10 .2016$.

Фролов Александр Альбертович - кандидат политических наук, старший преподаватель кафедры социально-политических теорий, Ярославский государственный университет им. П. Г. Аемидова. Адрес: 150000, Россия, г. Ярославль, ул. Советская, д. 10. Тел.: +7 (910) 810-45-90. Эл. aspec: a.a.froloff@gmail.com

Frolov Aleksandr Albertovich, Candidate of Political Sciences, Senior Lecturer, Department of Social and Political Theories, Demidov Yaroslavl State University. Postal address: 10 Sovetskaya St., 150000 Yaroslavl, Russian Federation. Tel.: +7 (910) 810-45-90. E-mail: a.a.froloff@gmail.com 